\title{
Size-resolved and bulk activation properties of aerosols in the North China Plain
}

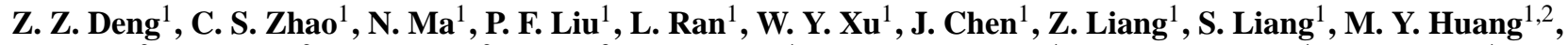 \\ X. C. Ma $^{2}$, Q. Zhang ${ }^{2}$, J. N. Quan ${ }^{2}$, P. Yan $^{3}$, S. Henning ${ }^{4}$, K. Mildenberger ${ }^{4}$, E. Sommerhage ${ }^{4}$, M. Schäfer ${ }^{4}$, \\ F. Stratmann ${ }^{4}$, and A. Wiedensohler ${ }^{4}$ \\ ${ }^{1}$ Department of Atmospheric and Oceanic Sciences, School of Physics, Peking University, Beijing, China \\ ${ }^{2}$ Beijing Weather Modification Office, Beijing Meteorological Bureau, Beijing, China \\ ${ }^{3}$ Centre for Atmosphere Watch and Services, Chinese Academy of Meteorological Sciences, China Meteorological \\ Administration, Beijing, China \\ ${ }^{4}$ Leibniz Institute for Tropospheric Research, Leipzig, Germany
}

Received: 11 December 2010 - Published in Atmos. Chem. Phys. Discuss.: 18 January 2011

Revised: 14 April 2011 - Accepted: 18 April 2011 - Published: 27 April 2011

\begin{abstract}
Size-resolved and bulk activation properties of aerosols were measured at a regional/suburban site in the North China Plain (NCP), which is occasionally heavily polluted by anthropogenic aerosol particles and gases. A Cloud Condensation Nuclei $(\mathrm{CCN})$ closure study is conducted with bulk $\mathrm{CCN}$ number concentration $\left(N_{\mathrm{CCN}}\right)$ and calculated CCN number concentration based on the aerosol number size distribution and size-resolved activation properties.

The observed $\mathrm{CCN}$ number concentration $\left(N_{\mathrm{CCN}-\mathrm{obs}}\right)$ are higher than those observed in other locations than China, with average $N_{\mathrm{CCN}-\text { obs }}$ of roughly $2000,3000,6000,10000$ and $13000 \mathrm{~cm}^{-3}$ at supersaturations of $0.056,0.083,0.17$, 0.35 and $0.70 \%$, respectively. An inferred critical dry diameter $\left(D_{\mathrm{m}}\right)$ is calculated based on the $N_{\mathrm{CCN}-\text { obs }}$ and aerosol number size distribution assuming homogeneous chemical composition. The inferred cut-off diameters are in the ranges of 190-280, 160-260, 95-180, 65-120 and 50-100 nm at supersaturations of $0.056,0.083,0.17,0.35$ and $0.7 \%$, with their mean values $230.1,198.4,128.4,86.4$ and $69.2 \mathrm{~nm}$, respectively.

Size-resolved activation measurements show that most of the $300 \mathrm{~nm}$ particles are activated at the investigated supersaturations, while almost no particles of $30 \mathrm{~nm}$ are activated even at the highest supersaturation of $0.72 \%$. The activation ratio increases with increasing supersaturation and particle
\end{abstract}

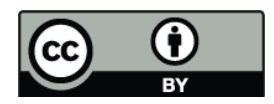

Correspondence to: C. S. Zhao (zcs@pku.edu.cn) size. The slopes of the activation curves for ambient aerosols are not as steep as those observed in calibrations with ammonium sulfate suggesting that the observed aerosols is an external mixture of more hygroscopic and hydrophobic particles.

The calculated $\mathrm{CCN}$ number concentrations $\left(N_{\mathrm{CCN}-\mathrm{calc}}\right)$ based on the size-resolved activation ratio and aerosol number size distribution correlate well with the $N_{\mathrm{CCN} \text {-obs }}$, and show an average overestimation of $19 \%$. Sensitivity studies of the CCN closure show that the $N_{\mathrm{CCN}}$ at each supersaturation is well predicted with the campaign average of sizeresolved activation curves. These results indicate that the aerosol number size distribution is critical in the prediction of possible CCN. The CCN number concentration can be reliably estimated using time-averaged, size-resolved activation efficiencies without accounting for the temporal variations.

\section{Introduction}

The impact of aerosol on cloud and the corresponding feedbacks of cloud are currently considered as the largest uncertainty in climate system (IPCC, 2007). Great efforts have been made to predict the number concentration of cloud condensation nuclei $(\mathrm{CCN})$ for modeling applications (Boucher and Lohmann, 1995; Khvorostyanov and Curry, 2006). Closure studies where measured and predicted $\mathrm{CCN}$ number concentrations $\left(N_{\mathrm{CCN}}\right)$ are compared, provide a test for quantitative understanding of $\mathrm{CCN}$ activation properties, and in particular, for parameterization schemes used in large-scale

Published by Copernicus Publications on behalf of the European Geosciences Union. 
models. Closure between the measured and the predicted $\mathrm{CCN}$ number concentrations would be achieved, when the differences between them fall within the uncertainties of measurements and predictions.

It has been well documented that the Raoult and Kelvin effects would together determine how an aerosol particle could turn into a possible CCN (Rogers and Yau, 1989). The relative importance of aerosol number size distribution and aerosol chemical composition in aerosol activation has already been discussed in several studies. Aerosol chemical composition is more important at lower supersaturations than at higher supersaturations, because the relative change in $\mathrm{CCN}$ number concentration induced by the change of aerosol composition is larger for circumstances with low CCN number concentration at lower supersaturations (Kuwata et al., 2005). The ability of particles to act as CCN is largely controlled by aerosol size rather than composition (Junge and McLaren, 1971; Fitzgerald, 1973; Dusek et al., 2006). Mixing state indicating the heterogeneity of the chemical composition of a particle distribution also needs to be accounted for (Anttila, 2010; Medina et al., 2007).

The measurements of aerosol size distribution and chemical composition are often utilized to predict the CCN number concentration. Bulk chemical composition of aerosol particles with diameter smaller than 10 or $1 \mu \mathrm{m}$ from filter sampling is often used in closure studies (Bougiatioti et al., 2009), while the knowledge of a size-resolved composition could possibly improve the prediction of $\mathrm{CCN}$ number concentration (Medina et al., 2007). Stroud et al. (2007) measured chemical composition of aerosols with an aerosol mass spectrometer (AMS), and predicted CCN number concentration with a kinetic model. CCN number concentrations were substantially over predicted (by $35.8 \pm 28.5 \%$ ) using size-averaged chemical composition, and by introducing size-dependent chemical composition the closure was improved considerably (average error $17.4 \pm 27 \%$ ).

Size-resolved activation ratios (the fraction of the activated particles in the total aerosol number) are frequently determined in laboratory and field studies. Such methods, described in detail by Frank et al. (2006), are used in instrument calibrations in laboratory and applied in measurements of aerosol activation properties. Size-resolved activation properties of known compounds, such as water-soluble organic and inorganic substances (Hori et al., 2003; Cruz and Pandis, 1997), mixtures of known compounds (Giebl et al., 2002), and natural mixtures (Dinar et al., 2006; Wex et al., 2007; Ziese et al. 2008) are intensively investigated in laboratory studies.

The concentrations of various pollutants are dramatically increasing in recent decades in China due to rapid economic development. The North China Plain (NCP) is one of the most polluted regions in the world, according to the satellite data of the aerosol loading and trace gas concentrations $(\mathrm{CO}$, $\mathrm{SO}_{2}, \mathrm{NO}_{\mathrm{x}}$, etc.) (Xu et al., 2011). The high level of aerosol loading (mass and number) and trace gases concentrations could possibly change the physical and chemical properties of the atmosphere, as well as cloud processes. A case in point is that the precipitation in North China has decreased significantly during the last 40 years and the reduction trend of precipitation is found to be correlated to increasing aerosol concentrations (Zhao et al., 2006).

In this work, the aerosol activation properties in the NCP are investigated, using the aerosol number size distributions, the size-resolved activation ratios, and the bulk $\mathrm{CCN}$ number concentrations. This work presents a method to better understand the relationship between aerosol number size distribution and $\mathrm{CCN}$ number concentration. Finally, a closure study is performed between the measured ( $\left.N_{\mathrm{CCN}-\text { obs }}\right)$ and calculated $\mathrm{CCN}$ number concentrations involving aerosol size distribution and size-resolved activation ratio.

\section{Relationship between aerosol size distribution and CCN number concentration}

This section presents the relationship between the aerosol number size distribution and $\mathrm{CCN}$ number concentration to help understanding the current work.

A bulk CCN number concentration can be measured employing a CCN counter (CCNC) set at a given supersaturation. The $\mathrm{CCN}$ is a subset of the total aerosol population. A schematic plot shows the relationship between aerosol number size distribution and CCN in Fig. 2.

\subsection{Internally mixed aerosol}

Assuming uniform chemical composition throughout the size range, a critical dry particle diameter $D_{\mathrm{m}}$ (pink line in Fig. 2) can be calculated from the $N_{\mathrm{CCN}-\text { obs }}$ and aerosol size distribution. The number concentration of aerosol particles with sizes larger than $D_{\mathrm{m}}$ equals to $N_{\mathrm{CCN}-\text { obs }}$.

$N_{\mathrm{CCN}-\mathrm{int}}=N_{\mathrm{CCN}-\mathrm{obs}}=\int_{D_{m}}^{\infty} n\left(\log D_{p}\right) d \log D_{p}$

where $D_{p}$ is the diameter of aerosol particle, and $n\left(\log D_{p}\right)$ is the function of the aerosol number size distribution.

\subsection{Partially externally mixed aerosol}

Atmospheric aerosol particles have complicated sizedependent chemical compositions due to various physical and chemical processes involved. Even at a certain particle size, their chemical composition may be quite different if the aerosol is heterogeneous mixed. For atmospheric aerosol particles with various chemical compositions, the $\mathrm{CCN}$ concentration can be calculated using the following equation,

$$
\begin{aligned}
& N_{\mathrm{CCN}-\mathrm{ext}}=\int_{0}^{\infty} n_{\mathrm{CCN}}\left(\log D_{p}\right) d \log D_{p} \\
& =\int_{0}^{\infty} A\left(\log D_{p}\right) n\left(\log D_{p}\right) d \log D_{p}
\end{aligned}
$$


Table 1. Critical Dry Diameter of $\mathrm{NaCl},\left(\mathrm{NH}_{4}\right)_{2} \mathrm{SO}_{4}$ and an Insoluble but Wettable (IBW) Particle.

\begin{tabular}{llll}
\hline$S S(\%)$ & \multicolumn{3}{c}{ Critical Dry Diameter $(\mathrm{nm})$} \\
\hline & $\mathrm{NaCl}$ & $\left(\mathrm{NH}_{4}\right)_{2} \mathrm{SO}_{4}$ & $\mathrm{IBW}$ \\
0.05 & 162 & 204 & 4206 \\
0.07 & 129 & 164 & 3004 \\
0.10 & 102 & 130 & 2103 \\
0.20 & 65 & 83 & 1052 \\
0.30 & 49 & 64 & 702 \\
0.40 & 41 & 53 & 527 \\
0.50 & 35 & 46 & 422 \\
0.60 & 31 & 41 & 351 \\
0.70 & 28 & 37 & 301 \\
0.80 & 26 & 34 & 264 \\
0.90 & 24 & 31 & 235 \\
1.00 & 22 & 29 & 211 \\
\hline
\end{tabular}

where $n_{\mathrm{CCN}}\left(\log D_{p}\right)$ is the $\mathrm{CCN}$ number size distribution function, and $A\left(\log D_{p}\right)$ is the size-resolved activation ratio.

The size-resolved activation ratio $A\left(\log D_{p}\right)$ is determined by aerosol particle size and chemical composition. In order to understand the role of size and composition on the sizeresolved activation ratio, two extreme conditions for aerosol composition are introduced and discussed here. First, we consider highly soluble particle substance (HSP), such as $\mathrm{NaCl}$ aerosols or ammonia sulfate aerosols. A critical dry diameter $D_{\text {HSP }}$ for the highly soluble particles can be calculated using Köhler equation (blue line in Fig. 2). Particles with sizes smaller than $D_{\text {HSP }}$ cannot be activated at the corresponding supersaturation.

For another extreme case, we consider an insoluble but wettable particle (IBW). Here, a Kelvin diameter ( $D_{\text {Kelvin, }}$, green line in Fig. 2) is determined using the Kelvin equation (Rogers and Yau, 1989; Pruppacher and Klett, 1997; Seinfeld and Pandis, 2006). The particles larger than $D_{\text {Kelvin }}$ are all activated.

The critical dry diameters of $\mathrm{NaCl},\left(\mathrm{NH}_{4}\right)_{2} \mathrm{SO}_{4}$ and IBW aerosol particles at various supersaturations are shown in Table 1. Typical supersaturation for stratiform clouds, cumulus clouds, and fog are $0.05 \%, 0.25-0.8 \%$, and $0.1 \%$, respectively (Seinfeld and Pandis, 2006). Ammonium sulfate particles larger than $34 \mathrm{~nm}$, respectively sodium chloride particles for sizes larger than $26 \mathrm{~nm}$ may be activated at supersaturation of $0.8 \%$. The size of an IBW particle needs to be above several micrometers to be activated at very low supersaturations in stratiform clouds. The activation ratio of aerosols is 0 at $D_{\mathrm{HSP}}$ and 1 at $D_{\text {Kelvin }}$. The activation ability of ambient aerosols in the real atmosphere varies between these two extreme cases of highly soluble substance and IBW. In this paper, ambient aerosol activation properties are investigated in field measurements using CCNC and mobility size spectrometer.

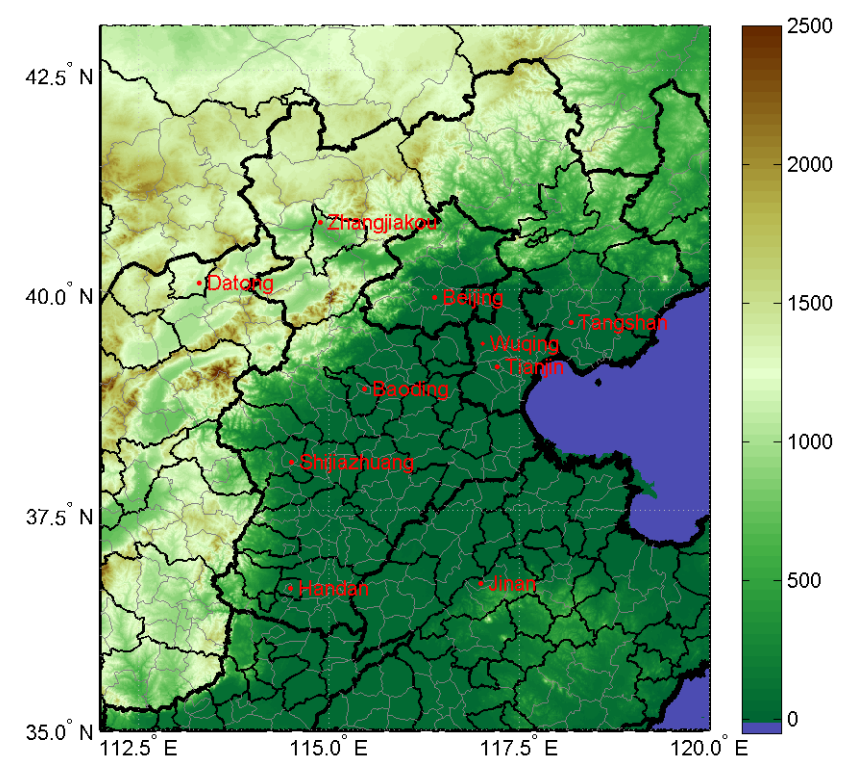

Fig. 1. Map for the measurement site. The color represents the elevation with data from Jarvis et al. (2008). The main cities in this area are marked in the map.

\section{Measurements and data processing}

\subsection{The field site}

The NCP has been undergoing a rapid development during the last three decades. Heavy industries and dense population have been causing severe particulate and gaseous pollution episodes, especially over the main cities in this area $\mathrm{Xu}$ et al., 2011). Wuqing is a town located in the NCP between the two Megacities of Beijing and Tianjin (Fig. 1). Investigations of the physical and chemical properties of the atmosphere were conducted at a regional/suburban site in Wuqing $\left(39^{\circ} 23^{\prime} \mathrm{N}, 117^{\circ} 01^{\prime} \mathrm{E}, 7.4 \mathrm{~m}\right.$ a.s.l.). The site is at the edge of the town with low traffic flow, and there are no large emission sources in the immediate surrounding areas.

The field study, focusing on aerosol, $\mathrm{CCN}$ activation properties and aerosol optical properties, was carried out in January 2010. The aerosol number size distribution and the bulk CCN number concentration were measured from Dec. 31, 2009 to Jan. 20, 2010. The size-resolved activation ratios were measured only at daytime.

\subsection{Instrumentations}

The data used in this work include the aerosol number size distribution, the CCN number concentration and the sizeresolved CCN activation ratio. The set-up of instruments is shown in Fig. 3. The instruments were equipped in the air-conditioned measurement container with a temperature around $20^{\circ} \mathrm{C}$. The ambient aerosol sample is drawn in through a $\mathrm{PM}_{10}$ impactor inlet $(16.67 \mathrm{~L} / \mathrm{min})$ at a height of 


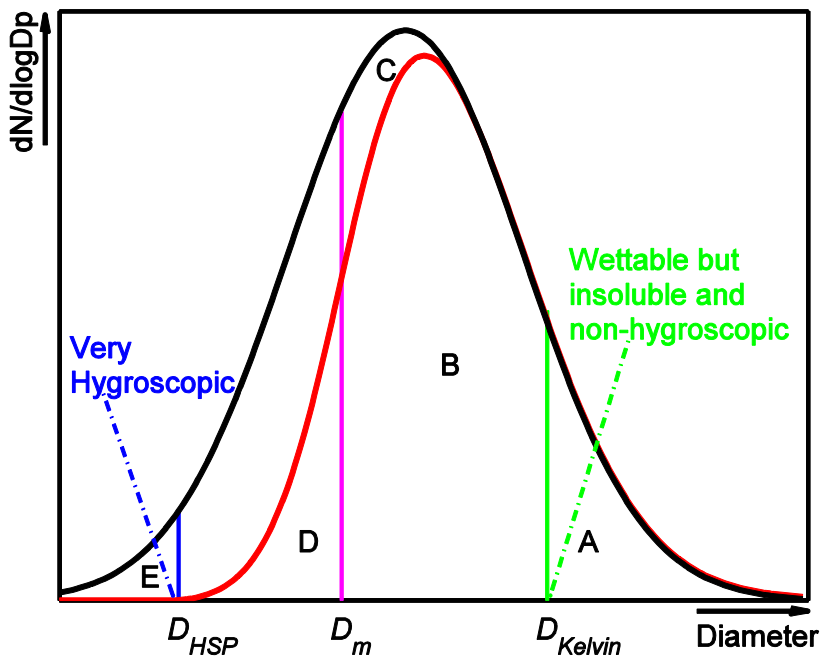

Fig. 2. Schematic of the relationship between aerosol and CCN The black curve represents the aerosol size distribution, while only the particles under the red curve act as CCN. $D_{\mathrm{m}}$ is regarded as an inferred critical dry diameter at the given SS. The number concentration of the aerosols larger than $D_{\mathrm{m}}$ equals to the $N_{\mathrm{CCN}}$. $D_{\mathrm{NaCl}}$ is the critical dry diameter of $\mathrm{NaCl}$ particle at the given $\mathrm{SS}$. $D_{\text {Kelvin }}$ is the critical diameter for an insoluble but wettable particle (IBW) at the given SS. All the aerosol particles with diameter larger than $D_{\text {Kelvin }}$ (area A) can be activated, while the atmospheric aerosol particles smaller than $D_{\mathrm{NaCl}}$ (area E) cannot be activated. The area $\mathrm{C}$ and $\mathrm{D}$ equals to each other.

$7 \mathrm{~m}$ above the ground level, and subsequently passes through a silica gel diffusion drier, maintaining a relative humidity (RH) below $30 \%$.

Aerosol number size distributions $(13.8-750 \mathrm{~nm})$ were obtained by a scanning mobility particle sizer (SMPS, Model 3936, TSI, USA) with a time resolution of five minutes. The SMPS consist mainly of differential mobility analyzer (DMA, Model 3081, TSI, USA) and condensation particle counter (CPC, Model 3772, TSI, USA). The DMA sheath and sample flows were $3 \mathrm{lpm}$ and $0.3 \mathrm{lpm}$, respectively.

A continuous-flow dual CCN counter (CCN-200) (Roberts and Nenes, 2005; Lance et al., 2006) manufactured by Droplet Measurement Technologies (DMT, USA) was utilized to measure the $\mathrm{CCN}$ activation properties. The $\mathrm{CCN}$ 200 has two columns to measure different samples at different supersaturations at the same time. One column directly measures the dry polydisperse aerosol sample to obtain the bulk $\mathrm{CCN}$ concentration, while the other measures the sizeresolved activation properties. Both columns operated at the same supersaturations at the same time. Five supersaturations (nominally $0.07,0.10,0.20,0.40$, and $0.80 \%$ ) made up a cycle of half an hour, taking $10 \mathrm{~min}$ for $0.07 \%$ and $5 \mathrm{~min}$ for other supersaturations. The bulk CCN number concentrations at five supersaturations were available every half an hour.

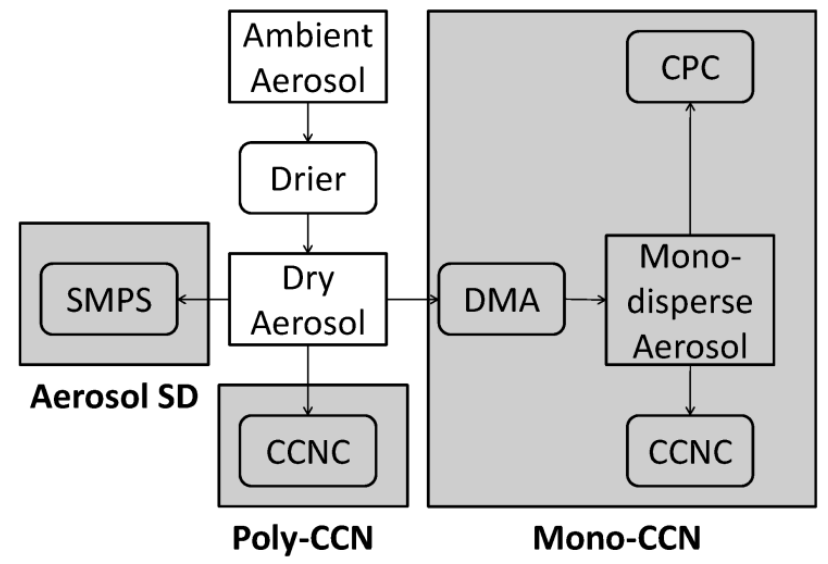

Fig. 3. Instrumentation set-up.

Quasi-monodisperse aerosol particles with diameters of $30,40,50,75,100,150,200$ and $300 \mathrm{~nm}$ were selected by another DMA (Model 3081, TSI, USA). The selected size of aerosol particles after the DMA was also changed every 30 minutes, during which the activation ratios for one size at five supersaturations were measured. Particle sizes with number concentrations with less than $10 \mathrm{~cm}^{-3}$ were skipped. The sheath and sample flow rates in DMA were $8 \mathrm{lpm}$ and 0.8 $1 \mathrm{pm}$, respectively. The sample flow was then split into two parts, $0.5 \mathrm{lpm}$ for CCNC and $0.3 \mathrm{lpm}$ for CPC (Model 3776, TSI, USA). CCNC reports the CCN number concentration for these size-selected aerosol particles $\left(N_{\mathrm{CCN} \text {-mono }}\right)$, and CPC reports the corresponding condensation nuclei number concentration $\left(N_{\mathrm{CN}-\mathrm{mono}}\right)$. The activation ratio is defined as the ratio between $N_{\mathrm{CCN} \text {-mono }}$ and $N_{\mathrm{CN} \text {-mono. Activation ra- }}$ tios of all the diameters at five supersaturations were available every $3-4 \mathrm{~h}$ depending on the number of selected particle sizes.

The CCNC was calibrated with ammonium sulfate particles (Rose et al., 2008) before and after the campaign. The critical dry diameters determined from the activation curves of ammonium sulfate, are converted to effective supersaturation $\left(S S_{e}\right)$ utilizing the Köhler equation (Pruppacher and Klett, 1997). The Köhler equation employs the temperature dependent surface tension of water (IAPWS Secretariat, 1994), temperature dependent solubility of ammonium sulfate in water (Seinfeld and Pandis, 2006), and molality dependent van't Hoff factor (Young and Warren, 1992; Low, 1969).

The temperature gradients (TG) and $S S_{e}$ were linearly fitted. The $S S_{e}$ of the atmospheric measurements is calculate from the TG with this $\mathrm{TG} \sim S S_{e}$ relationship. The calibration shows that the effective supersaturations were $0.058,0.085$, $0.18,0.36$ and $0.72 \%$ for size-resolved measurements, and $0.056,0.083,0.17,0.35$ and $0.70 \%$ for bulk measurements. 


\subsection{Data processing}

For each supersaturation, $N_{\mathrm{CCN}-\mathrm{obs}}$ is recorded every second. To ensure the instrument and data stability, these records are filtered with different criterions of temperature and flow, e.g., the temperatures and flow rates need to be close to the set values. The average $N_{\mathrm{CCN}-\text { obs }}$ at each supersaturation is computed using the processed records.

The CCN activation ratio is calculated based on both the $N_{\mathrm{CCN}-\mathrm{mono}}$ and $N_{\mathrm{CN} \text {-mono }}$ of the quasi-monodisperse aerosol particles. Each aerosol sample consists of aerosol particles with a small range of electrical mobility, due to the DMA transfer function. The particles may however carry different number of electric charges. This means that even for the same mobility, these particles can have different particle sizes. The DMA transfer function width and the multiple charges skew the activation curves.

A multiple charge correction is then applied for the $\mathrm{CCN}$ activation ratio without considering the width of DMA transfer function (as the Appendix A). The presence of multiply charged particles, which usually have higher activation ratio than the singly charged particle, induces a falsely higher measured activation ratio for singly charged diameters. The correction will reduce the activation ratio especially for the smaller particle sizes.

\section{Results}

\subsection{Summary of bulk CCN measurements}

Figure 4 shows the time series of the wind, aerosol number concentrations $\left(N_{\mathrm{CN}}\right)$ and $N_{\mathrm{CCN}-o b s}$ during the measurement period. The statistical results for the $N_{\mathrm{CN}}$ and $N_{\mathrm{CCN}-o b s}$ are summarized in Table 2. The $N_{\mathrm{CN}}$ ranged from 2000 to $59000 \mathrm{~cm}^{-3}$. Most of the time, the $N_{\mathrm{CN}}$ was however between 10000 and $40000 \mathrm{~cm}^{-3}$.

The $N_{\mathrm{CCN}-\text { obs }}$ depended strongly in the different weather systems during the measurement period. High $N_{\mathrm{CCN}-\text { obs }}$ were observed during periods of heavy aerosol pollution when the wind speed was low. The $N_{\mathrm{CCN}-\text { obs }}$ was found to be as high as $28000 \mathrm{~cm}^{-3}$ at $0.70 \%$ supersaturation. Normally, the $N_{\mathrm{CCN}-\text { obs }}$ was however about 2000,3000 and $6000 \mathrm{~cm}^{-3}$ at supersaturation of $0.056,0.083$ and $0.17 \%$, and more than $10000 \mathrm{~cm}^{-3}$ at supersaturations above $0.35 \%$. On other hand, under meteorological situation with strong winds, the $N_{\mathrm{CCN}-\text { obs }}$ can be as low as around $100 \mathrm{~cm}^{-3}$ at supersaturations of 0.056 and $0.083 \%$, and less than $2000 \mathrm{~cm}^{-3}$ at $0.70 \%$ supersaturation, because the aerosol number concentration in the accumulation mode range becomes relatively low.

The inferred critical diameters $D_{\mathrm{m}}$, as defined in Eq. (1) in Sect. 2.1, are calculated based on the $N_{\mathrm{CCN} \text {-obs }}$ and the corresponding aerosol number size distribution. The $D_{\mathrm{m}}$ at each supersaturation varies dramatically (Fig. 5). Variations of $D_{\mathrm{m}}$ at supersaturations above $0.17 \%$ are larger than
Table 2. Statistics of the Aerosol Number Concentration and CCN Number Concentration. The $N_{\mathrm{CCN}}\left(\mathrm{cm}^{-3}\right)$ at five supersaturations and the aerosol number concentration $\left(N_{\mathrm{CN}}, \mathrm{cm}^{-3}\right)$ are presented. The minimum, maximum, mean value and the corresponding standard deviation are presented. The last line is the number of samples.

\begin{tabular}{lllllll}
\hline & $0.056 \%$ & $0.083 \%$ & $0.17 \%$ & $0.35 \%$ & $0.70 \%$ & $\mathrm{~N}_{\mathrm{CN}}$ \\
\hline Min & 76 & 142 & 482 & 1115 & 1840 & 1924 \\
Max & 6084 & 7135 & 11539 & 21151 & 28488 & 59003 \\
Mean & 2192 & 2957 & 5977 & 10279 & 12963 & 14651 \\
Std & 1653 & 2012 & 3135 & 4879 & 5725 & 7483 \\
$\mathrm{~N}$ & 930 & 934 & 931 & 926 & 921 & 5453 \\
\hline
\end{tabular}

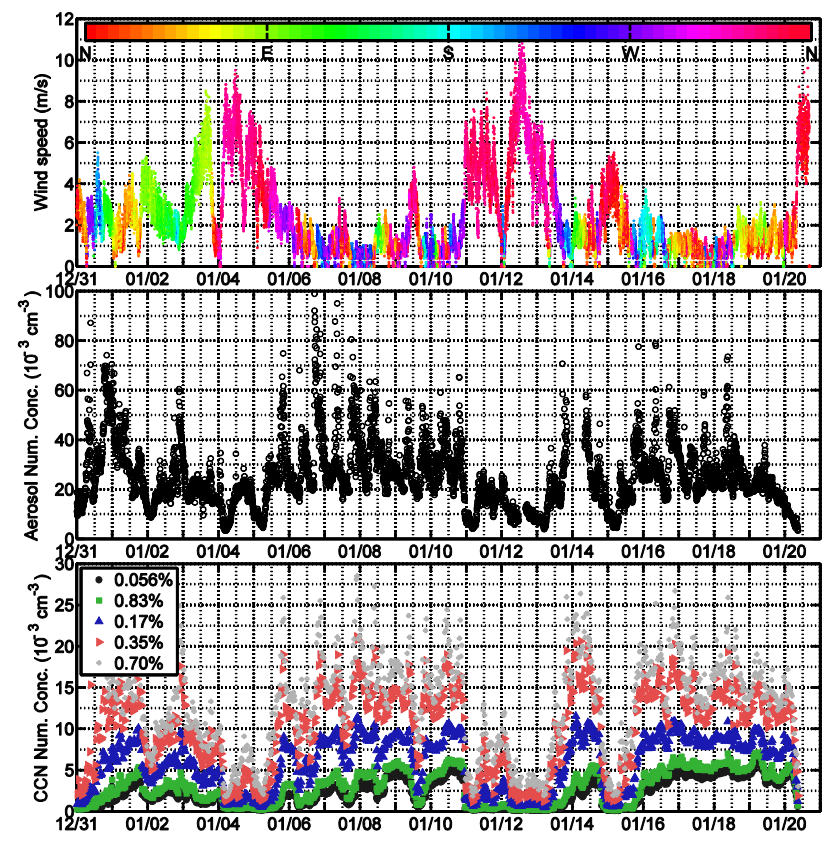

Fig. 4. Time series of wind (a), Aerosol (b) and CCN (c) number concentrations.

that at 0.056 and $0.083 \%$ supersaturations. The $D_{\mathrm{m}}$ are in the ranges of 190-280, 160-260, 95-180, 65-120 and 50$100 \mathrm{~nm}$ at supersaturations of $0.056,0.083,0.17,0.35$ and $0.7 \%$, with their mean values $230.1,198.4,128.4,86.4$ and $69.2 \mathrm{~nm}$, respectively. The average aerosol number concentration within these size ranges are 2000, 2900, 5800, 6900 and $8100 \mathrm{~cm}^{-3}$. These values are comparable to the campaign average $N_{\mathrm{CCN}-\mathrm{obs}}$. The predicted $\mathrm{CCN}$ number concentrations (using Eq. 1) with the mean critical dry diameters inferred from the measurements result in an average relative deviation of nearly $69 \%$, and a bias of $-26 \%$ (see the definition in caption of Fig. 9). This indicates that it is impossible to predict $\mathrm{CCN}$ number concentration from the aerosol number size distribution using a fixed critical dry diameter. 


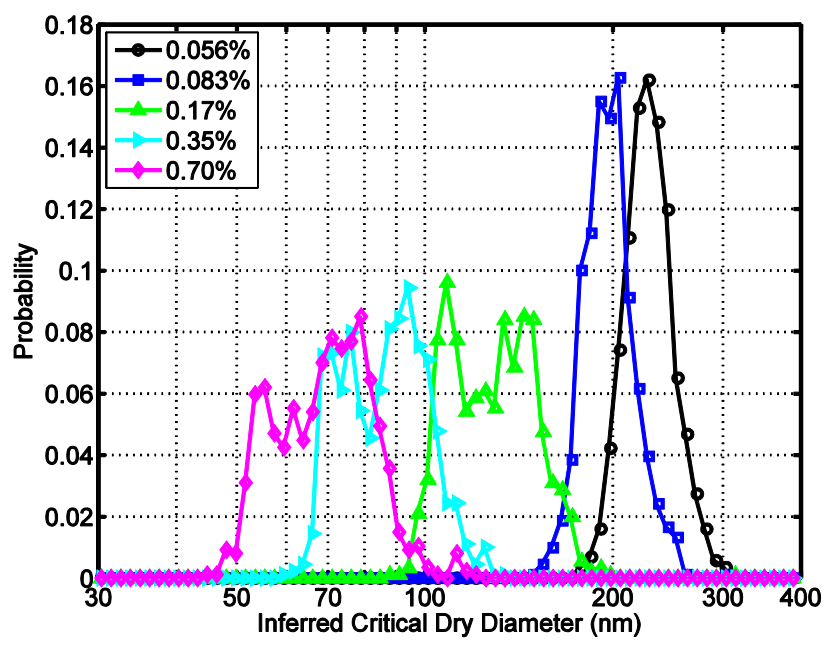

Fig. 5. Probability distribution of the inferred critical dry diameter.

\subsection{Size-resolved activation ratio}

Figure 6 shows the time series of the activation ratios for 75 , 100 , and $200 \mathrm{~nm}$ particles at different supersaturations.

At lower supersaturations and for smaller particles, e.g. $75 \mathrm{~nm}$ at 0.058 and $0.085 \%$ supersaturations, the activation ratios are close to 0 , because the particles are too small to be activated. Particles larger than $75 \mathrm{~nm}$ are mostly activated at supersaturations above $0.36 \%$. It can be seen in Fig. 6 that the activation ratios for $200 \mathrm{~nm}$ particles at $0.056 \%$ and $0.085 \%$, for $100 \mathrm{~nm}$ particles at $0.18 \%$, and for $75 \mathrm{~nm}$ particles at $0.36 \%$ mainly ranged between 0.2 and 0.8 .

Figure 7 shows the size-resolved activation curve at each supersaturation averaged for the campaign. The activation curves for ambient aerosols are shown in colored lines. The activation curves at different supersaturations are distinct. Particles smaller than $150 \mathrm{~nm}$ are rarely activated at supersaturation $0.058 \%$, while $40 \mathrm{~nm}$ particles have activation ratios of 0.4 at $0.72 \%$ supersaturation.

Most $300 \mathrm{~nm}$ particles activate at all measured supersaturations. Although $300 \mathrm{~nm}$ is much smaller than the Kelvin diameter for most of the measured supersaturations (Table 1), small soluble fraction enables the particle to be activated. For example, ammonium sulfate fractions of $18,8,2,0.3$ and $0.03 \%$ (and the rest is insoluble) are sufficient to activate a $300 \mathrm{~nm}$ particle at supersaturations of $0.07,0.1,0.2$, 0.4 and $0.6 \%$, respectively. Almost no particles of $30 \mathrm{~nm}$ are activated at the measured supersaturations, because even pure ammonium sulfate particles of $30 \mathrm{~nm}$ are unable to be activated at $0.8 \%$ supersaturation. The activation ratios are strongly dependent on the particle size. The activation ratio increases with increasing diameter.

The slope of the activation curves of ammonium sulfate represents internally mixed aerosol (gray curves in Fig. 7). The slopes for ambient aerosols are not as steep as that of ammonium sulfate, suggesting that the aerosol is chemically and/or morphologically externally mixed (Frank et al., 2006). For each size, hygroscopic growth and activation of particles depend on their chemical components and mixing state. The external mixing is also observed in the hygroscopicity measurements in Wuqing (Liu et al., 2011). And the GFPDF (Probability Distribution Function of Growth Factor) of a size selected aerosol, in turn, can provide the activation ratio at various supersaturations (Su et al., 2010).

\subsection{Calculation of $\mathrm{CCN}$ number concentration based on aerosol number size distribution and size-resolved activation ratio}

The CCN number concentration can be calculated from the aerosol number size distribution and the size-resolved activation ratios (Eq. 2). The calculation of $N_{\mathrm{CCN}}$ using this method is evaluated in this study with parallel measurements of $N_{\mathrm{CCN}}$ and size-resolved activation properties (Fig. 8).

The two columns of the CCNC are independent and they are used for bulk and size-resolved measurements. Both columns are set to the same five supersaturations, nominally $0.07,0.10,0.20,0.40$ and $0.80 \%$, during the measurement. However, the calibration showed that the effective supersaturations are different (Sect. 3.2).

The measured $N_{\mathrm{CCN}}$ is compared with the calculated $N_{\mathrm{CCN}}$ at the same supersaturation in $\mathrm{CCN}$ closure study. The measured $N_{\mathrm{CCN}}$ and effective supersaturation are fitted with an empirical function

$N_{\mathrm{CCN}}(S)=N_{0}\left(1-e^{-k\left(S-S_{0}\right)}\right)$,

where $S$ is supersaturation, $N_{0}, k$ and $S_{0}$ are fitted parameters.

This function describes the $N_{\mathrm{CCN}} \sim S$ relationship in this study better than $N_{\mathrm{CCN}}=C S^{k}$ suggested by Twomey (1959). $N_{\mathrm{CCN}}$ at the effective supersaturations of the size-resolved measurements are achieved by fitting the CCN spectra with Eq. (3). This is referred to as the "measured" $N_{\mathrm{CCN}}$ $\left(N_{\mathrm{CCN}-\mathrm{meas}}\right)$, and then used to be compared with the calculated $N_{\mathrm{CCN}}\left(N_{\mathrm{CCN} \text {-calc }}\right)$.

\subsubsection{Calculation with measured aerosol number size distribution and size-resolved activation ratio}

$N_{\mathrm{CCN} \text {-calc }}$ can be calculated from the above corrected data with Eq. (2). The calculated $N_{\mathrm{CCN}-\text { calc }}\left(N_{\mathrm{CCN} \text {-calc-realtime }}\right)$ based on the measured aerosol number size distribution and the size-resolved activation ratio, along with the bulk measurements, is shown in Fig. 9a. The $N_{\mathrm{CCN}-\text { calc-realtime }}$ is highly correlated with the measurements $\left(R^{2}=0.9501\right)$. However, the calculation generally overestimates the $N_{\mathrm{CCN}}$. The linear fitted lines have slopes larger than 1 for each supersaturation and 1.169 for all the data.

The difference between measured and calculated $N_{\mathrm{CCN}}$ might result from the measurement uncertainties. The 


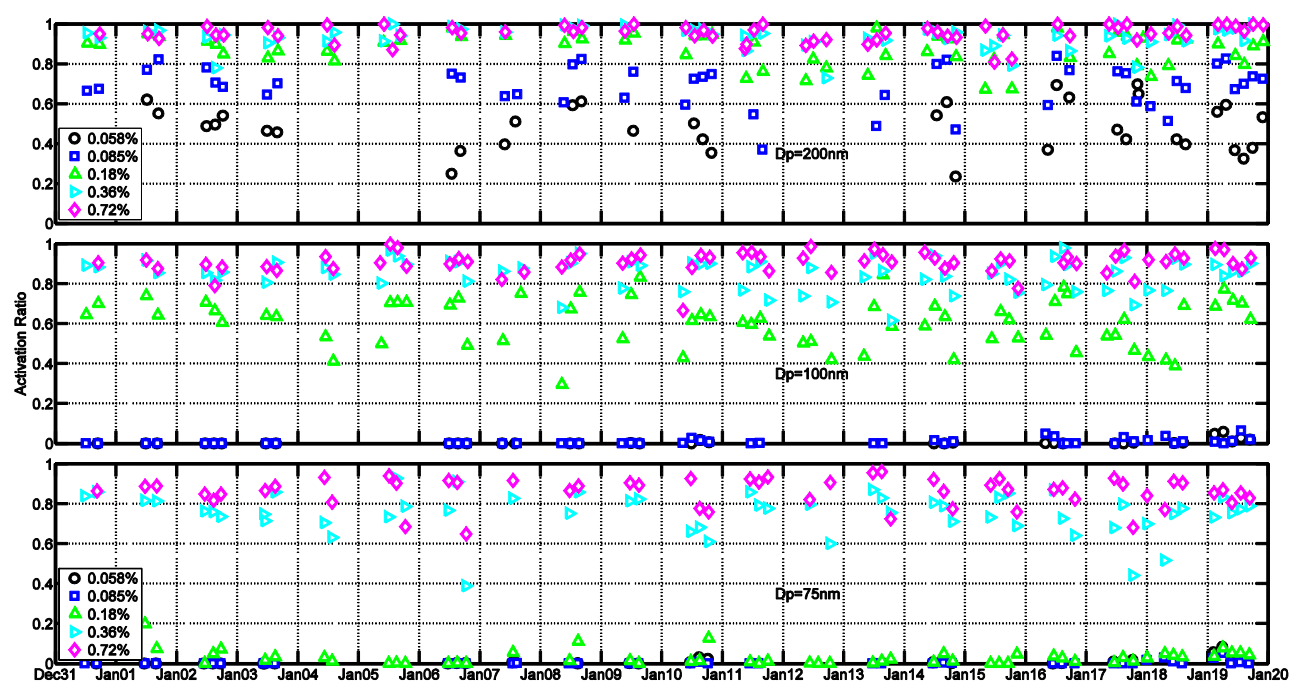

Fig. 6. Time series of the activation ratio during January 2010.

Average Activation Ratio

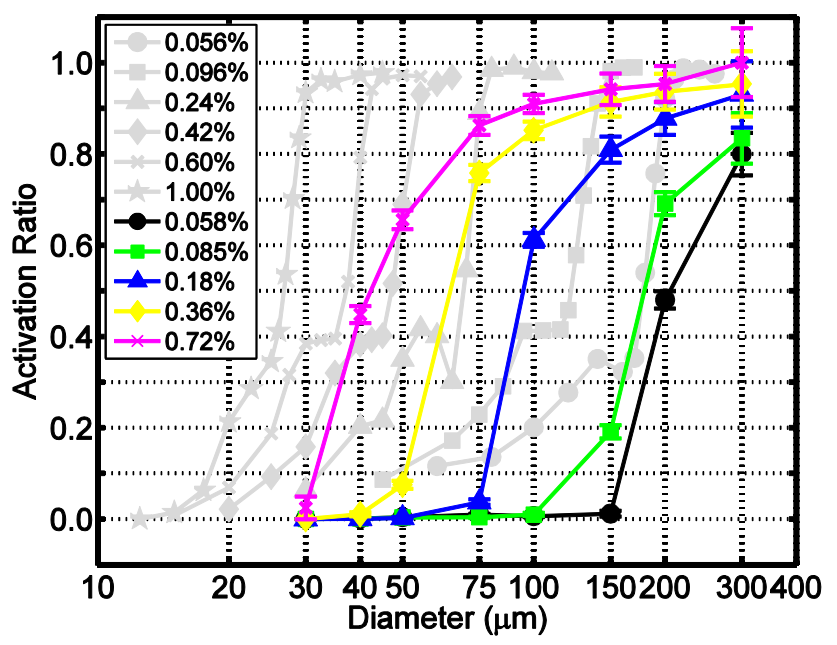

Fig. 7. Average activation curves for different supersaturations calibration curves of ammonia sulfate particles are shown as gray curves labeled with the effective supersaturation. The colored curves are the average activation curves of ambient aerosols.

uncertainty for aerosol number size distribution is under controlled conditions within 10\% (Wiedensohler et al., 2011). The uncertainty for CCN measurements comes from the uncertainty of supersaturation, the water depletion inside the $\mathrm{CCNC}$, and the particle counting and flow rate. The uncertainty of calibrated supersaturation, by comparing the calibration before and after the campaign, is small in this study. The water depletion may occur in the CCNC in the bulk $\mathrm{CCN}$ measurement. The high particle number concentration also may reduce the counting rate of the CCNC (manual of $\mathrm{CCNC}$ ). Taking these sources into account, the uncertainty

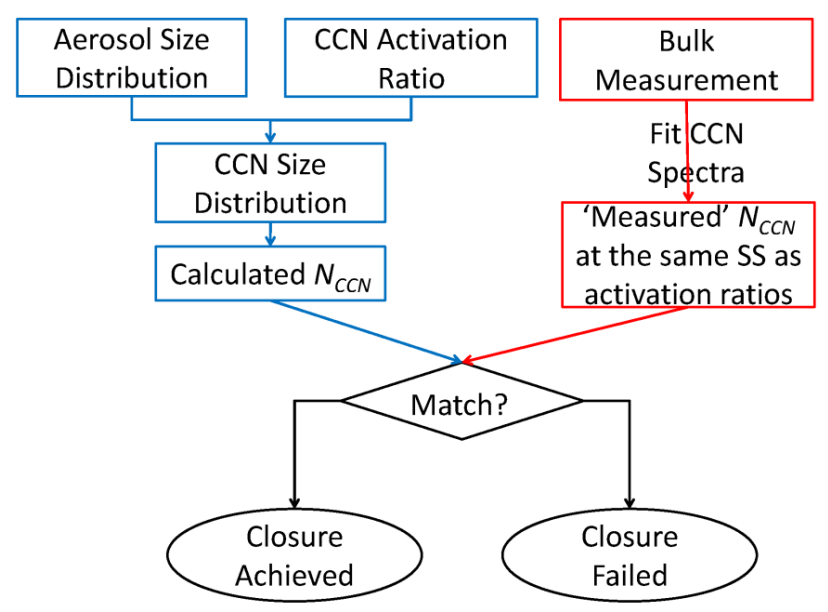

Fig. 8. Flowchart for CCN closure between bulk and size-resolved Measurements.

of bulk and size-selected $\mathrm{CCN}$ number concentration might exceed that of aerosol size distribution measurement. Moore et al. (2010) reported uncertainties of 0.17 for $N_{\mathrm{CCN}-m o n o}$, 0.067 for $N_{\mathrm{CN}-m o n o}$ and thus $18 \%$ for activation ratio when the $N_{\mathrm{CN} \text {-mono }}$ is $100 \mathrm{~cm}^{-3}$. Other uncertainties arise from the coarse size resolution of the activation ratio, the absence of DMA transfer function correction for the activation ratio and the linear interpolation of the activation ratio on the scale of $\log D_{p}$. The uncertainties are estimated to be $>10 \%$ for bulk $N_{\mathrm{CCN}-m e a s}$, and $>21 \%$ for calculated $N_{\mathrm{CCN} \text {-calc. The }}$ calculated CCN number concentrations agree well with the measured one within the estimated uncertainties of the measurements and the data processing. 

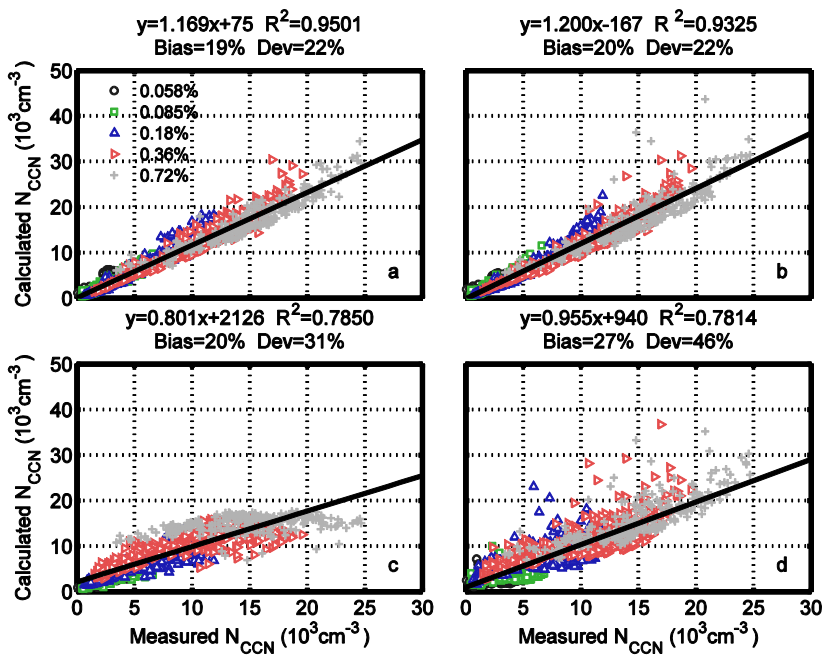

Fig. 9. Closure between Measured CCN Number Concentration and the $\mathrm{CCN}$ Number Concentration Calculated from Aerosol Number Size Distribution (SD) and Size-resolved Activation Ratio (SRAR) for Different Supersaturations (a): Realtime SD and SRAR; (b): Real-time SD and Averaged SRAR; (c): Average $\mathrm{N}_{\mathrm{CN}}$ (keep NASD) and Real-time SRAR; (d): Average NASD (keep $\mathrm{N}_{\mathrm{CN}}$ ) and Real-time SRAR. There are 1527 pairs of data in each panel. The title of each panel shows the fitted function, correlation coefficient, average relative bias (Bias $\left.=\left(N_{\mathrm{CCN} \text {-cal }}-N_{\mathrm{CCN} \text {-meas }}\right) / N_{\mathrm{CCN} \text {-meas }}\right)$ and average relative deviation $\left(\mathrm{Dev}=\left|N_{\mathrm{CCN}-\mathrm{cal}}-N_{\mathrm{CCN} \text {-meas }}\right| / N_{\mathrm{CCN}-\text { meas }}\right)$.

\subsubsection{Sensitivity study}

The calculation of $N_{\mathrm{CCN}-\text { calc }}$ employs the activation ratio curves and the aerosol number size distribution. The activation ratio curves (AR) represent the chemical composition and mixing state of aerosol. The aerosol size distribution can be described with two factors, i.e. the population of aerosol

$N_{\mathrm{CN}}=\int_{0}^{\infty} n\left(\log D_{p}\right) d \log D_{p}$,

and the normalized aerosol size distribution (NASD)

$n^{\prime}\left(\log D_{p}\right)=\frac{1}{N_{\mathrm{CN}}} n\left(\log D_{p}\right)$.

Sensitivity tests are performed to explore the relative importance of these three factors (AR, $N_{\mathrm{CN}}$ and NASD). The $N_{\mathrm{CCN} \text {-calc }}$ are calculated when one of the above factors is replaced by the average conditions.

The average AR based on 20-day measurements in January 2010 are given in Fig. 7. Figure $9 b$ shows the calculated $N_{\mathrm{CCN}-\text { calc }}\left(N_{\mathrm{CCN}-\text { calc-ConstAR }}\right)$ utilizing these averaged activation curves and the real-time measurement of aerosol size distribution. There are more scattered data than the base case (Fig. 9a). The relative bias is larger than the base case and the correlation coefficient $\left(R^{2}\right)$ is lower. Nevertheless, both relative bias and $R^{2}$ are close to those of the result using all real-time data. The replacement of the average activation ratio does not cause significant changes to the results. These average size-resolved activation ratio curves provide a good estimation of activation properties.

Figure 9c shows the result when particle number concentrations are fixed to the average one. The aerosol number size distributions are replaced with the product of the NASD and the average particle number concentration $\left(\overline{N_{\mathrm{CN}}}\right)$.

$n_{\mathrm{ConstNcn}}\left(\log D_{p}\right)=\frac{\overline{N_{\mathrm{CN}}}}{N_{\mathrm{CN}}} n\left(\log D_{p}\right)$,

$N_{\mathrm{CCN}-\mathrm{calc}-\mathrm{ConstNcn}}$

$=\int_{0}^{\infty} A\left(\log D_{p}\right) n_{\mathrm{ConstNcn}}\left(\log D_{p}\right) d \log D_{p}$,

where bar represents average in time. The $N_{\mathrm{CCN}-\text { calc-ConstNcn }}$ is linearly related to particle number concentration. The $N_{\mathrm{CCN}-\mathrm{calc}-\mathrm{ConstNcn}}$ is limited by the prescribed aerosol number concentration. The average relative deviation is larger than the base case and the correlation coefficient is lower. The linear fitted lines have slopes and intercepts highly biased from 1 and 0 , respectively.

The average NASD is obtained from the average of all normalized aerosol number size distributions. The aerosol number size distribution in the calculation is replaced with the product of the average NASD and the original particle number concentration.

$n_{\text {ConstNASD }}\left(\log D_{p}\right)=N_{\mathrm{CN}} \overline{n^{\prime}\left(\log D_{p}\right)}=N_{\mathrm{CN}} \overline{\left(\frac{n\left(\log D_{p}\right)}{N_{\mathrm{CN}}}\right)}$,

$N_{\mathrm{CCN}-\mathrm{calc}-\mathrm{ConstNASD}}$

$=\int_{0}^{\infty} A\left(\log D_{p}\right) n_{\text {ConstNASD }}\left(\log D_{p}\right) d \log D_{p}$

Compared to the previous cases, the average NASD case has much more scattered data; both the average relative bias and the average relative deviation are also larger (Fig. 9d).

From the results discussed for Fig. 9c and d, it can be seen that the aerosol number size distribution plays a critical role in calculation of $N_{\mathrm{CCN}}$. The evolution of aerosol number size distribution depends on the sources, coagulation, growth, aging and deposition processes. It is improper to calculate the $N_{\text {CCN }}$ with prescribed aerosol size distribution due to its significant variation.

\section{Summary and conclusion}

The aerosol-cloud interaction is an essential issue in climate change research. The relationship between aerosol and $\mathrm{CCN}$ is complicated, because the aerosols origin from various emissions, and undergo atmospheric physical and chemical processes. Measurements of size-resolved activation help 
us to better understand the ability of aerosol particles acting as CCN. The bulk and size-resolved activation properties of submicron aerosols were investigated in January 2010 at a regional/suburban site in the NCP.

High aerosol mass and number concentrations are connected with high $N_{\mathrm{CCN}-\text { obs }}$ in the NCP. The $N_{\mathrm{CCN}-\text { obs }}$ occasionally exceeds $20000 \mathrm{~cm}^{-3}$ at supersaturations above $0.35 \%$ during pollution episodes. Such high $N_{\mathrm{CCN}-\text { obs }}$ are also observed in the vicinity of Guangzhou (Rose et al., 2010) and south of Beijing (Wiedensohler et al., 2009).

However, the relationship between this abundant CCN at the surface and the cloud properties is not clear yet. Deng et al. (2009) presented the aircraft measurements of cloud droplet number concentration (CDNC) around Beijing. The CDNC are $376 \pm 290,257 \pm 226,147 \pm 112,60 \pm 35$ and $60 \pm 84 \mathrm{~cm}^{-3}$, for cumulus, stratocumulus, altocumulus, altostratus, and nimbostratus clouds, respectively. This observed CDNC around Beijing area are far lower than the surface measured CCN number concentration. Most of the aerosols are trapped inside the boundary layer. The aircraft measurements show that the aerosol number concentration decreases with height (Liu et al., 2009). Aerosol particles in the boundary layer do not always have opportunity to be activated into the cloud droplets above the boundary layer. There are also some mechanisms to transfer the surface aerosol into the free troposphere, such as convection. Local circulations like mountain valley breeze and sea land breeze may also alter the vertical profiles of aerosol. Chen et al. (2009) shows that the pollutants in the boundary layer can be injected from the planetary boundary layer and form an elevated pollution layer in the free troposphere due to the Mountain Chimney Effect.

The size-resolved activation measurements and CCN closure study provide insight of the detailed activation ability. More than 50\% of the particles larger than 200, 170, 90, 70, and $45 \mathrm{~nm}$ are activated at supersaturations of $0.058,0.085$, $0.18,0.36$ and $0.72 \%$, respectively. These diameters are a little larger than but close to the critical diameters of ammonium sulfate particles (Table 1). This implies that the aerosols in the North China Plain consist of highly soluble material. Soluble fractions of more than $83 \%$, calculated based on the Köhler Theory with assumed aerosol composition of ammonium sulfate and an insoluble core, are needed to activate these particles. The water soluble organics and the influence of surface tension are also expected to contribute to the activation (Petters and Kreidenweis, 2007; Gunthe et al., 2011).

The size-resolved activation curves, based on the measured aerosol size distributions, provide a method to calculate CCN size distribution and $N_{\mathrm{CCN}}$. Sensitivity studies of this method were performed to explore the relative importance of the size-resolved activation ratio, the aerosol number concentration and normalized aerosol size distribution. The calculated $N_{\mathrm{CCN}}$ are highly biased when the aerosol number concentration or normalized aerosol size distribution are fixed to the average level. This shows that both the aerosol number concentration and normalized aerosol size distribution are of great importance in the prediction of $\mathrm{CCN}$ number concentration. Junge and McLaren (1971) found that aerosol size distribution is the most important factor in determining the $\mathrm{CCN}$ spectra, with compositional variations being significant only for aerosols with less than $10 \%$ soluble material. Fitzgerald's (1973) study also showed that the shape of the CCN spectra is quite insensitive to aerosol solubility. Recent work also concluded that size matters more than chemistry for cloud-nucleating ability of aerosol particles (Dusek et al., 2006; McFigans et al., 2006; Ervens et al., 2007; Andreaeand Rosenfeld; 2008). Thus the campaign-average size-resolved activation ratios can be used to describe the activation properties of the aerosols in the NCP. The variation of aerosol chemical composition affects the solubility, the surface tension and the non-ideality of the solution. The variation of size-resolved activation ratio caused by aerosol chemical composition has weak impacts on bulk aerosol activation. This average size-resolved activation ratios during this campaign and measured aerosol size distribution can be used to predict $N_{\mathrm{CCN}}$ successfully. These results would help us to understand the role of size and chemical compositions in their activation processes, and enables us to develop an aerosol-CCN scheme based on such size-resolved measurements.

\section{Appendix A}

\section{The procedure of multiple charge correction}

The aerosol sample selected by DMA is a quasi-monodisperse aerosol with a width of mobility range and several charges for each particle. A simple multiple charge correction is applied for the $\mathrm{CCN}$ activation ratio without consideration of the DMA transfer function. Thus only the central mobility is considered in the aerosol sample.

Assuming the activation ratio for the particle with $j$ charges passing through channel $i$ is $A_{i j}, i=1,2, \ldots, I$, the measured activation ratio can be expressed as

$$
\begin{aligned}
& M_{i}=\frac{\sum_{J=1}^{J} N_{\mathrm{CCN} i j}}{\sum_{J=1}^{J} N_{\mathrm{CPC} i j}}=\frac{\sum_{J=1}^{J} A_{i j} N_{\mathrm{CPC} i j}}{\sum_{J=1}^{J} N_{\mathrm{CPC} i j}} \\
& =\frac{\sum_{J=1}^{J} A_{i j} \mathrm{MCF}_{i j}}{\sum_{J=1}^{J} \mathrm{MCF}_{i j}}=\sum_{J=1}^{J} A_{i j} F_{i j}
\end{aligned}
$$

where $J$ is the maximum number of charges on one particle, here we use $10 . N_{\mathrm{CPC} i j}$ is the number of particles passing through channel $i$ with $j$ charges. It can be calculated from the parallel aerosol size distribution and the charge probability (Wiedensohler, 1988), considering the DMA transfer function. 
The relative multiple charge fraction is

$\mathrm{MCF}_{i j}=N_{\mathrm{CPC} i j} / N_{\mathrm{CPC} i 1}$,

and

$F_{i j}=\mathrm{MCF}_{i j} / \sum_{k=1}^{J} \mathrm{MCF}_{i k}$.

$A_{i j}$ can be expressed as the linear interpolation of the activation ratios at the measured diameters,

$A_{i j}=A_{i(j)}+\left(A_{i(j)+1}-A_{i(j)}\right) \frac{\log D_{i j}-\log D_{i(j)}}{\log D_{i(j)+1}-\log D_{i(j)}}$

$=A_{i(j)} \frac{\log D_{i(j)+1}-\log D_{i j}}{\log D_{i(j)+1}-\log D_{i(j)}}+A_{i(j)+1} \frac{\log D_{i j}-\log D_{i(j)}}{\log D_{i(j)+1}-\log D_{i(j)}}$

$=A_{i(j)} \frac{\log \left(D_{i(j)+1} / D_{i j}\right)}{\log \left(D_{i(j)+1} / D_{i(j)}\right)}+A_{i(j)+1} \frac{\log \left(D_{i j} / D_{i(j)}\right)}{\log \left(D_{i(j)+1} / D_{i(j)}\right)}$

$=A_{i(j)} P_{i j}+A_{i(j)+1} Q_{i j}$.

where $D_{i j}$ is the diameter of the particles passing through channel $i$ with $j$ charges, $i(j)$ is the index of the largest one among the measured diameters which are smaller than or equals to $D_{i j}, A_{i}$ indicates the activation ratio of the singly charged particles in the corresponding channels.

When $i(j)$ equals to the number of the measured sizes, $D_{i(j)+1}$ and $A_{i(j)+1}$ can be replaced with the corresponding theoretical critical dry diameter of water ball (Kelvin equation) $D_{K}$ and the activation ratio of 1 . When no measured diameter is smaller than or equals to $D_{i j}, D_{i(j)}$ and $A_{i(j)}$ are replaced with $D_{\mathrm{HSP}}$ and $0, D_{i(j)+1}$ and $A_{i(j)+1}$ are $D_{1}$ and $A_{1}$.

With Eq. (A4), Eq. (A1) can be written as

$M_{i}=\sum_{j=1}^{J} A_{i j} F_{i j}$

$=\sum_{j=1}^{J}\left(A_{i(j)} P_{i j}+A_{i(j)+1} Q_{i j}\right) F_{i j}=\sum_{i=1}^{I} S_{i j} A_{i}+T_{i}$,

where $S_{i j}$ and $T_{i}$ are both expressed as the results of $P_{i j}, Q_{i j}$ and $F_{i j} . T_{i}$ comes from the terms where $D_{i(j)+1}$ is replaced with Kelvin diameter.

$S_{i j}=\sum_{j=1}^{J}\left(\delta(i(k), i) P_{i j}+\delta(i(k)+1, i) Q_{i k}\right) F_{i k}$.

$T_{i}=\sum_{j=1}^{J} \delta(i(k)+1, i) Q_{i k} F_{i k}$.

A new response is written as $R_{i}=M_{i}-T_{i}$. This equation set is then expressed as

$\boldsymbol{R}=\mathbf{S} \boldsymbol{A}$,

where $\boldsymbol{R}$ and $\boldsymbol{A}$ are $I \times 1$ vectors and $\mathbf{S}$ is an $I \times I$ matrix. Solving the equation set with non-negative least square method will get the activation ratio of singly charged particles.
Acknowledgements. This work is supported by the National 973 Project of China (2011CB403402), the National Natural Science Foundation of China (NSFC) under grants 40875001, 40975083, 40905060, and the German Science Foundation under grant DFG WI 1449/14-1.

Edited by: V.-M. Kerminen

\section{References}

Andreae, M. O. and Rosenfeld, D.: Aerosol-cloud-precipitation interactions. Part 1. The nature and sources of cloud-active aerosols, Earth-Sci. Rev., 89, 13-41, 2008.

Anttila, T.: Sensitivity of cloud droplet formation to the numerical treatment of the particle mixing state, J. Geophys. Res., 115, D21205, doi:10.1029/2010jd013995, 2010.

Boucher, O. and Lohmann, U.: The sulfate-CCN-cloud albedo effect, Tellus B, 47, 281-300, doi:10.1034/j.16000889.47.issue3.1.x, 1995.

Bougiatioti, A., Fountoukis, C., Kalivitis, N., Pandis, S. N., Nenes, A., and Mihalopoulos, N.: Cloud condensation nuclei measurements in the marine boundary layer of the eastern mediterranean: CCN closure and droplet growth kinetics, Atmos. Chem. Phys., 9, 7053-7066, doi:10.5194/acp-9-7053-2009, 2009.

Chen, Y., Zhao, C., Zhang, Q., Deng, Z., Huang, M., and Ma, X.: Aircraft study of mountain chimney effect of Beijing, china, J. Geophys. Res., 114, D08306, doi:10.1029/2008jd010610, 2009.

Cruz, C. N. and Pandis, S. N.: A study of the ability of pure secondary organic aerosol to act as cloud condensation nuclei, Atmos. Environ., 31, 2205-2214, 1997.

Deng, Z., Zhao, C., Zhang, Q., Huang, M., and Ma, X.: Statistical analysis of microphysical properties and the parameterization of effective radius of warm clouds in Beijing area, Atmos. Res., 93, 888-896, 2009.

Dinar, E., Taraniuk, I., Graber, E. R., Katsman, S., Moise, T., Anttila, T., Mentel, T. F., and Rudich, Y.: Cloud condensation nuclei properties of model and atmospheric hulis, Atmos. Chem. Phys., 6, 2465-2482, doi:10.5194/acp-6-2465-2006, 2006.

Dusek, U., Frank, G. P., Hildebrandt, L., Curtius, J., Schneider, J., Walter, S., Chand, D., Drewnick, F., Hings, S., Jung, D., Borrmann, S., and Andreae, M. O.: Size matters more than chemistry for cloud-nucleating ability of aerosol particles, Science, 312, 1375-1378, doi:10.1126/science.1125261, 2006.

Ervens, B., Cubison, M., Andrews, E., Feingold, G., Ogren, J. A., Jimenez, J. L., DeCarlo, P., and Nenes, A.: Prediction of cloud condensation nucleus number concentration using measurements of aerosol size distributions and composition and light scattering enhancement due to humidity, J. Geophys. Res., 112, D10S32, doi:10.1029/2006jd007426, 2007.

Fitzgerald, J. W.: Dependence of the supersaturation spectrum of CCN on aerosol size distribution and composition, J. Atmos. Sci., 30, 628-634, 1973.

Frank, G. P., Dusek, U., and Andreae, M. O.: Technical note: A method for measuring size-resolved $\mathrm{CCN}$ in the atmosphere, Atmos. Chem. Phys. Discuss., 6, 4879-4895, doi:10.5194/acpd-64879-2006, 2006.

Giebl, H., Berner, A., Reischl, G., Puxbaum, H., Kasper-Giebl, A., and Hitzenberger, R.: CCN activation of oxalic and malonic acid 
test aerosols with the university of Vienna cloud condensation nuclei counter, J. Aerosol Sci., 33, 1623-1634, 2002.

Gunthe, S. S., Rose, D., Su, H., Garland, R. M., Achtert, P., Nowak, A., Wiedensohler, A., Kuwata, M., Takegawa, N., Kondo, Y., Hu, M., Shao, M., Zhu, T., Andreae, M. O., and Pöschl, U.: Cloud condensation nuclei $(\mathrm{CCN})$ from fresh and aged air pollution in the megacity region of Beijing, Atmos. Chem. Phys. Discuss., 11, 9959-9997, 10,

http://www.atmos-chem-phys-discuss.net/11/9959/10/.5194/acpd11-9959-2011, 2011.

Hori, M., Ohta, S., Murao, N., and Yamagata, S.: Activation capability of water soluble organic substances as CCN, J. Aerosol Sci., 34, 419-448, 2003.

IAPWS Secretariat: IAPWS Release on Surface Tension of Ordinary Water Substance, Issued by the International Association for the Properties of Water and Steam, available online at: http://www.iapws.org/relguide/surf.pdf, 1994.

IPCC: Climate Change 2007: The Physical Science Basis, Cambridge University Press, Cambridge, UK and New York, NY, USA, 996 pp, 2007.

Jarvis, A., Reuter, H. I., Nelson, A., Guevara, E.: Hole-filled seamless SRTM data V4, International Centre for Tropical Agriculture (CIAT), available online at: http://srtm.csi.cgiar.org, 2008.

Junge, C. and McLaren, E.: Relationship of cloud nuclei spectra to aerosol size distribution and composition, J. Atmos. Sci., 28, 382-390, 1971.

Khvorostyanov, V. I. and Curry, J. A.: Aerosol size spectra and CCN activity spectra: Reconciling the lognormal, algebraic, and power laws, J. Geophys. Res., 111, D12202, doi:10.1029/2005jd006532, 2006.

Kuwata, M., Kondo, Y., Miyazaki, Y., Komazaki, Y., Kim, J. H., Yum, S. S., Tanimoto, H., and Matsueda, H.: Cloud condensation nuclei activity at Jeju island, Korea in spring 2005, Atmos. Chem. Phys., 8, 2933-2948, doi:10.5194/acp-8-2833-2008, 2008.

Lance, S., Medina, J., Smith, J. N., and Nenes, A.: Mapping the operation of the dmt continuous flow CCN counter, Aerosol Sci. Tech., 40, 242-254, 2006.

Liu, P. F., Zhao, C. S., Gbel, T., Hallbauer, E., Nowak, A., Ran, L., Xu, W. Y., Deng, Z. Z., Ma, N., Mildenberger, K., Henning, S., Stratmann, F., and Wiedensohler, A.: Hygroscopic properties of aerosol particles at high relative humidity and their diurnal variations in the North China Plain, Atmos. Chem. Phys., 11, 3479-3494, doi:10.5194/acp-11-3479-2011, 2011.

Liu, P., Zhao, C., Zhang, Q., Deng, Z., Huang, M., Ma, X., and Tie, X.: Aircraft study of aerosol vertical distributions over Beijing and their optical properties, Tellus B, 61, 756-767, 2009.

Low, R. D. H.: A generalized equation for the solution effect in droplet growth, J. Atmos. Sci., 26, 608-611, 1969.

McFiggans, G., Artaxo, P., Baltensperger, U., Coe, H., Facchini, M. C., Feingold, G., Fuzzi, S., Gysel, M., Laaksonen, A., Lohmann, U., Mentel, T. F., Murphy, D. M., O’Dowd, C. D., Snider, J. R., and Weingartner, E.: The effect of physical and chemical aerosol properties on warm cloud droplet activation, Atmos. Chem. Phys., 6, 2593-2649, doi:10.5194/acp-6-2593-2006, 2006.

Medina, J., Nenes, A., Sotiropoulou, R.-E. P., Cottrell, L. D., Ziemba, L. D., Beckman, P. J., and Griffin, R. J.: Cloud condensation nuclei closure during the international consortium for atmospheric research on transport and transformation 2004 campaign: Effects of size-resolved composition, J. Geophys. Res., 112, D10S31, doi:10.1029/2006jd007588, 2007.

Moore, R. H., Nenes, A., and Medina, J.: Scanning mobility CCN analysis-a method for fast measurements of size-resolved $\mathrm{CCN}$ distributions and activation kinetics, Aerosol Sci. Technol., 44, 861-871, 2010.

Petters, M. D. and Kreidenweis, S. M.: A single parameter representation of hygroscopic growth and cloud condensation nucleus activity, Atmos. Chem. Phys., 7, 1961-1971, doi:10.5194/acp-71961-2007, 2007.

Pruppacher, H. R. and Klett, J. D.: Microphysics of clouds and precipitation, Dordrecht, The Netherlands, Kluwer Academic Publishers, 954 pp., 1997.

Roberts, G. C. and Nenes, A.: A continuous-flow streamwise thermal-gradient CCN chamber for atmospheric measurements, Aerosol Sci. Tech., 39, 206-221, 2005.

Rogers, R. R. and Yau, M. K.: A short course in cloud physics, 3rd ed., Pergamon Press, Oxford, New York, USA, 293 pp., 1989.

Rose, D., Nowak, A., Achtert, P., Wiedensohler, A., Hu, M., Shao, M., Zhang, Y., Andreae, M. O., and Pöschl, U.: Cloud condensation nuclei in polluted air and biomass burning smoke near the mega-city Guangzhou, China - part 1: Size-resolved measurements and implications for the modeling of aerosol particle hygroscopicity and CCN activity, Atmos. Chem. Phys., 10, 33653383, doi:10.5194/acp-10-3365-2010, 2010.

Rose, D., Gunthe, S. S., Mikhailov, E., Frank, G. P., Dusek, U., Andreae, M. O., and Pöschl, U.: Calibration and measurement uncertainties of a continuous-flow cloud condensation nuclei counter (DMT-CCNC): CCN activation of ammonium sulfate and sodium chloride aerosol particles in theory and experiment, Atmos. Chem. Phys., 8, 1153-1179, doi:10.5194/acp-8-11532008, 2008.

Seinfeld, J. H. and Pandis, S. N.: Atmospheric chemistry and physics: From air pollution to climate change, 2 ed., John Wiley \& Sons, Inc., New York, 1225 pp., 2006.

Stroud, C. A., Nenes, A., Jimenez, J. L., DeCarlo, P. F., Huffman, J. A., Bruintjes, R., Nemitz, E., Delia, A. E., Toohey, D. W., Guenther, A. B., and Nandi, S.: Cloud activating properties of aerosol observed during celtic, J. Atmos. Sci., 64, 441-459, 2007.

Su, H., Rose, D., Cheng, Y. F., Gunthe, S. S., Massling, A., Stock, M., Wiedensohler, A., Andreae, M. O., and Pöschl, U.: Hygroscopicity distribution concept for measurement data analysis and modeling of aerosol particle mixing state with regard to hygroscopic growth and CCN activation, Atmos. Chem. Phys., 10, 7489-7503, doi:10.5194/acp-10-7489-2010, 2010.

Twomey, S.: The nuclei of natural cloud formation part ii: The supersaturation in natural clouds and the variation of cloud droplet concentration, Pure Appl. Geophys., 43, 243-249, 1959.

Wex, H., Hennig, T., Salma, I., Ocskay, R., Kiselev, A., Henning, S., Massling, A., Wiedensohler, A., and Stratmann, F.: Hygroscopic growth and measured and modeled critical supersaturations of an atmospheric hulis sample, Geophys. Res. Lett., 34, L02818, doi:10.1029/2006GL028260, 2007.

Wiedensohler, A.: An approximation of the bipolar charge distribution for particles in the submicron size range, J. Aerosol Sci., 19, 387-389, 1988.

Wiedensohler, A., Cheng, Y. F., Nowak, A., Wehner, B., Achtert, P., Berghof, M., Birmili, W., Wu, Z. J., Hu, M., Zhu, T., Takegawa, 
N., Kita, K., Kondo, Y., Lou, S. R., Hofzumahaus, A., Holland, F., Wahner, A., Gunthe, S. S., Rose, D., Su, H., and Pöschl, U.: Rapid aerosol particle growth and increase of cloud condensation nucleus activity by secondary aerosol formation and condensation: A case study for regional air pollution in northeastern china, J. Geophys. Res., 114, D00G08, 10.1029/2008jd010884, 2009.

Wiedensohler, A., Birmili, W., Nowak, A., Sonntag, A., Weinhold, K., Merkel, M., Wehner, B., Tuch, T., Pfeifer, S., Fiebig, M., Fjäraa, A. M., Asmi, E., Sellegri, K., Depuy, R., Venzac, H., Villani, P., Laj, P., Aalto, P., Ogren, J. A., Swietlicki, E., Roldin, P., Williams, P., Quincey, P., Hüglin, C., Fierz-Schmidhauser, R., Gysel, M., Weingartner, E., Riccobono, F., Santos, S., Grüning, C., Faloon, K., Beddows, D., Harrison, R. M., Monahan, C., Jennings, S. G., O’Dowd, C. D., Marinoni, A., Horn, H. G., Keck, L., Jiang, J., Scheckman, J., McMurry, P. H., Deng, Z., Zhao, C. S., Moerman, M., Henzing, B., and de Leeuw, G.: Particle mobility size spectrometers: Harmonization of technical standards and data structure to facilitate high quality long-term observations of atmospheric particle number size distributions, Atmos. Meas. Tech. Discuss., 3, 5521-5587, doi:10.5194/amtd-3-55212010, 2010.
Xu, W. Y., Zhao, C. S., Ran, L., Deng, Z. Z., Liu, P. F., Ma, N., Lin, W. L., Xu, X. B., Yan, P., He, X., Yu J., Liang, W. D., and Chen, L. L.: Characteristics of pollutants and their correlation to meteorological conditions at a suburban site in the North China Plain, Atmos. Chem. Phys. Discuss., 11, 71137154, doi:10.5194/acpd-11-7113-2011, 2011.

Young, K. C. and Warren, A. J.: A reexamination of the derivation of the equilibrium supersaturation curve for soluble particles, J. Atmos. Sci., 49, 1138-1143, 1992.

Zhao, C., Tie, X., and Lin, Y.: A possible positive feedback of reduction of precipitation and increase in aerosols over eastern central china, Geophys. Res. Lett., 33, L11814, 10.1029/2006g1025959, 2006.

Ziese, M., Wex, H., Nilsson, E., Salma, I., Ocskay, R., Hennig, T., Massling, A., and Stratmann, F.: Hygroscopic growth and activation of hulis particles: Experimental data and a new iterative parameterization scheme for complex aerosol particles, Atmos. Chem. Phys., 8, 1855-1866, doi:10.5194/acp-8-1855-2008, 2008. 